characterized using sensitive preparations that discriminate between compounds with high and low affinities and between partial agonists and pure antagonists ${ }^{15}$. Kinins contribute to both contractile and secretory processes: the former are blocked by $B_{1}$ or $B_{2}$ receptor antagonists, while the latter tend not to be. Some secre. tory processes may therefore be activated by kinins through receptors other than $B_{1}$ and $B_{2}$ receptors (e.g. ' ${ }^{\prime}{ }_{3}$ ). Further developments in the area of kinin antagonists may help identify possible bradykinin receptor subtypes ${ }^{18} ; \quad B_{2}$ receptor antagonists also have therapeutic potential as analgesics or anti-inflammatory agents ${ }^{19}$.

\section{Acknowledgements}

The authors thank Mrs C. Théberge for typing the manuscript and F. Nantel for preparing the Tables. The contribution of the graduate students D. Jukic, 5. Télémaque, F. Nantel, N-E. Rouissi to the experimental work has been greatly appreciated. All experimental data were obtained with the financial support of the Medical Research Council of Canada (MRCC). DR is a Career Investigator of the MRCC; GD and SD are Fellows of the Fonds de la Recherche en Santé du Québec.

\section{References}

1 Ėrdös, E., ed. (1979) Bradykimin, Kailidin and Kallikrein (Handbook of Experimental Pharmacology Suppl. to Vol. 25). Springer Verlag

2 Regoli, D. and Barabé, I. (1980) Pharmacol. Rev. 32, 1-46

3 Vavrek, R. I. and Stewart, I. H. (19:5) Peptides 6, 161-164

4 Rifo, I. Pourrat, M., Vavrek, R. J. Stewart, 1. M. and Huidobrotaro, J. P. (1987) Ettr. J. Pharmacol. 142, 305-312

5 Sieranka, L. R. et al. (1988) proc. Natl Acad. Sci. LISA 85, 3245-3249

6 Regoli, D., Rhaleb, N-E, Drapeau, G. and Dion, S. (1990) l. Cardiovasc. Pharmacol. 15, S30-538

7 Devillier, P., Renoux, M., Drapeau, G. and Regoli, D. (1988) Eur. I. Pharmacol. $149,137-140$

8 Regoli, D. ct al. (1986) Eur. 1. Pharmacol, $123,61-65$

9 D'Orléans-Juste, P., Dion, S., Mizrahi, J and Regoli, D. (1985) Eur. I. Pharmacol. $114,9-21$
10 Rhaleb, N-E., Dion, S. Rouissi, N. Drapeau, G. and Regoli, D. Eitr. pharmacol. (in press)

11 Farmer. S. C., Burch, R. M., Meeker S. A. and Wilkins, D. E. (1989) Mol. Phamacol. 36, 1-8

12 Rhaleb, N-E. ¿t al (1988) Eur. /. Pharmacol. 151, 275-279

13 Stewari, ]. M. and Vavrek, R. I. (1988) in Peptides: Clemistry and Biology (Marshall, G. R., ed.), pp. 433-437, Escom, Lejden

14 Drapeau, G., Rha'eb, N-E., Dion, S. Jukic, D. and Regoli, D. (1988) Eur. Pharmacol. 155, 193-195

15 Rhaleb, N-E. ef al. Br. 1. Pharmacol. (in piess)

16 Regeli, D. (1985) Trents Phamacd. Sci. 6. $481-484$

17 Arunlakshana, O. and Schild, H. O. (1959) Br. I. Pharmacol. 14, 48-58

18 Plevin, R. and Owen, P. J. (1988) Trends Pliarmicol, Sci. 9, 387-389

19 Taylor, I. E., DeFeudis, F. V. and Mortau, 1. P. 11989? Drig Dev. Res. 16. $1-11$

20 Tallarida, R. I. and Murray, R. B. (1981) Mamual of Pharmocologic Calculations with Computer Progtams, SpringerVerlag

21 Rhaleb, N-E. et al. (1990) Br. l. Pharmacot. $99,445-448$

Mergetpa: Dt-2-mercaptomethyl-3guanidinoethylpropanoic acid

\title{
Free radicals and ischemic tissue injury
}

\section{Steven W. Werns and Benedict R. Lucchesi}

There is growing evidence that reperfusion of ischemic organs is associated with the formution of free radicals that exacerbate the ischemic injury. Free radicals may damage viable tissue via the peroxidation of lipids and oxidation of protein sulfhydryl groups, leading to perturbations of membrane permeability and enzyme function. Steven Werns and Benedict Lucchesi discuss evidence that activated neutrophils are an important source of free radicals after cardiac and intestinal ischemin, and assess the strategics that have been investigated as ways of alleviating damage caused by free radicals during ischemia-reperfusion.

The early restoration of myocardial blood flow after the onset of myocardial ischemia is essential in o-der to arrest the progression of myocardial cell death and to permit the functional recovery

5. W. Werms is Assistant Professor af Itternal Medicine at the Division of Cardiology, Department of Internal Medicine, and $B . R$. Lucchesi is Professor at the Department of Pharmacology, The University of Michigant Medical School, 6322 Medical Sciences Building 1, Ann Arbor, MI 48109, USA. of reversibly injured myocardium. There is, however, evidence that repertusion of ischemic myocardium is also associated wilh the formation of oxygen radicais and that these radicals caust additional myocardial damag'.. A wide variety of cells, organelles and enzymes may be involved in the free radical formation activated by ischemia and reperfusion; these include neutrophils, xanthine oxidase, cyclooxygenase and lipoxygenase, autooxidation of catechol- amines, mitochondria and the sarcoplasmic reticulum (see Refs 1 and 2 for review).

\section{Oxygen radicals}

The sequential, univalent reduction of molecular oxygen results in the formation of superoxide anion $\left(\mathrm{O}_{2}^{-}\right)$, hydrugen peroxide $\left(\mathrm{H}_{2} \mathrm{O}_{2}\right)$, and hydroxyl radical $(\mathrm{OH})$ (Fig. 1). Superoxide anions and hydroxyl radicals are classified as free radicals by virtue of their unpaired electrons. The formation of hydroxyl radical from $\mathrm{H}_{2} \mathrm{O}_{2}$ can be catalysed by iron derived from ferritin, hemoglobin, or myoglobin'.

Free radicals may exert diverse biochemical effects on both intracellular and extracellular molecules (Table I), and there is extensive evidence that cardiac structure and function calt be ditsied by these effects. Perfusion of isolated hearts with a source of oxygen radicals causes a depression of contractile function accompanied by decreased myocardial concentrations of ATP and phosphocreatine; there is ultrastructural evidence of mitochondrial and endothelial damage ${ }^{3}$. Isolated 
TABLE I. Efiects of free radicals on biological molecules

\begin{tabular}{ll}
\hline Target & Effect \\
\hline Lipids & $\begin{array}{l}\text { peroxidation of latty acids, altering } \\
\text { permeability }\end{array}$ \\
Proteins & $\begin{array}{l}\text { oxidation of sulfhydryl groups, } \\
\text { resulting in: activation of latent } \\
\text { enzymes, e g. collagenase: } \\
\text { inactivation of a, -antitrypsin: } \\
\text { inactivation of enzymes }\end{array}$ \\
DNA & $\begin{array}{l}\text { strand scission, resulting in } \\
\text { consumption of NAD and } \\
\text { impairment of ATP synthesis }\end{array}$
\end{tabular}

cardiac sarcoplasmic reticulum exhibiled impaired $\mathrm{Ca}^{2+}$ transport after exposure to oxygen radicals 4 .

\section{Antioxidant mechanisms}

A number of antioxidant mechanisms prevent oxidative damage by the reactive products of oxygen that are formed during normal metabolic events ${ }^{1,2}$. The primary intracellular defense mechanisms against this type of damage are superoxide dismutase (SOD), glutathione peroxidase, catalase, and vitamin $E$ localized in the lipid membrane. SOD catalyses the formation of hydrogen peroxide from superoxide anions (Fig. 2). The decomposition of hydrogen peroxide to water and oxygen can be catalysed by the enzymes catalase and glutathione peroxidase (Fig. 2). The subsequent reduction of hydrogen peroxide or lipid peroxides by glutathione peroxidase is accompanied by the oxidation of glutathione, resulting in the formation of glutathione disulfide. The myocardial concentrations of free radical scavengers such as glutathione, glutathione peroxidase and superoxide dismutase are reduced by hypoxia, which may increase the susceptibility of the hypoxic cells to injury by free radicals during reoxygenation of the tissue ${ }^{5}$.

The activities of SOD, catalase and glutathione peroxidase in the plasma are low or absent ${ }^{1}$. It has been suggested, therefore, that the primary extracellular defense against free radicals is proteins, such as ceruloplasmin, albumin and haptoglobin ${ }^{1}$, and circulating erythrocytes ${ }^{b}$. Erythrocytes are effective inhibitors of damage caused by hydrogen peroxide, but not that caused by superoxide anions $s^{6,7}$. Reperfusion of ischemic isolated rat hearts with erythrocytes increased ventricular function and decreased myocardial $\mathrm{H}_{2} \mathrm{O}$, (Ref. 7). Inhibition of erythrocyte catalase negated the protective effect, while inhibition of erythrocyte SOD did not. The results indicated that erythrocyte catalase can decrease endogenously generated $\mathrm{H}_{2} \mathrm{O}_{2}$ and related tissue injury.

Malondialdehyde and conjugated dienes are by-products of lipid peroxidation induced by free radicals. Several studies have found that malondialdehyde and conjugated dienes are formed during reperfusion of hypoxic or ischemic myocardium ${ }^{5,8}$, although a recent investigation found no evidence of lipid peroxidation associated with reperfusion after global cardiac ischemia. The reason for the discrepancy is unclear.

\section{Detection of free radicals in the ischemic heart}

The direct measurement of free radicals has been attempted using electron paramagnetic resonance (EPR) spectroscopy. Signals that are consistent with free radicals have been detected in the myocardium and coronary effluent of rabbit $^{10}$ and rat ${ }^{11}$ isolated hearts during reperfusion after global ischemia. Spin-trapping techniques have been used to demonstrate the formation of free radicals during regional myocardial ischemia of the canine heart. EPR signals characteristic of oxygen and carbon-centered radical adducts were detected in the coronary venous blood draining from the ischemic bed by the infusion of a spin trap during reperfusion after a brief ( $15 \mathrm{~min})$ period of coronary artery occlusion ${ }^{12,13}$. The production of free radicals by canine myocardium after $15 \mathrm{~min}$ of regional ischemia was markedly reduced by treatment with SOD plus catalase ${ }^{12}$ or N-2-mercaptopropionyl glycine (MPG), a sulfhydryl compound that is believed to be a scavenger of hydroxyl radicals ${ }^{13}$.

\section{Myocardial infarction and free radicals}

A variety of methods have been investigated to determine whether they can alleviate free radicai damage during myocardial infarction.

\section{Effects of free radical scavengers on infarction}

The effect of superoxide dismutase and other free radical 'scavengers' on the extent of experimental myocardial infarction has been the subject of numerous studies (see Ref. 14 for review). In our laboratory, the effects of treatment with MPG, a scavenger of hydroxyl radicals, or the enzymes SOD and catalase, on the extent of myocardial injury have been examined in dogs that were subjected to 90 min of coronary artery occlusion followed by reperfusion. Treatment that began either $15 \mathrm{~min}$ before ischemia or 15 min before reperfusion was equally effective in limiting myocardial injury ${ }^{15,16}$. Subsequently it was found that treatment with catalase alone does not reduce infarct size significantly, while the administration of SOD alone limits the extent of injury in dogs that underwent coronary artery occlusion for $90 \mathrm{~min}$ followed by perfusion for up to $48 \mathrm{~h}$ (Ref. 14).

Tamura et al. ${ }^{17}$ demonstrated a significant reduction of infarct size after $90 \mathrm{~min}$ of ischemia and four days of reperfusion in dogs treated with PEG-SOD (in which the polyethylene glycol conjugate

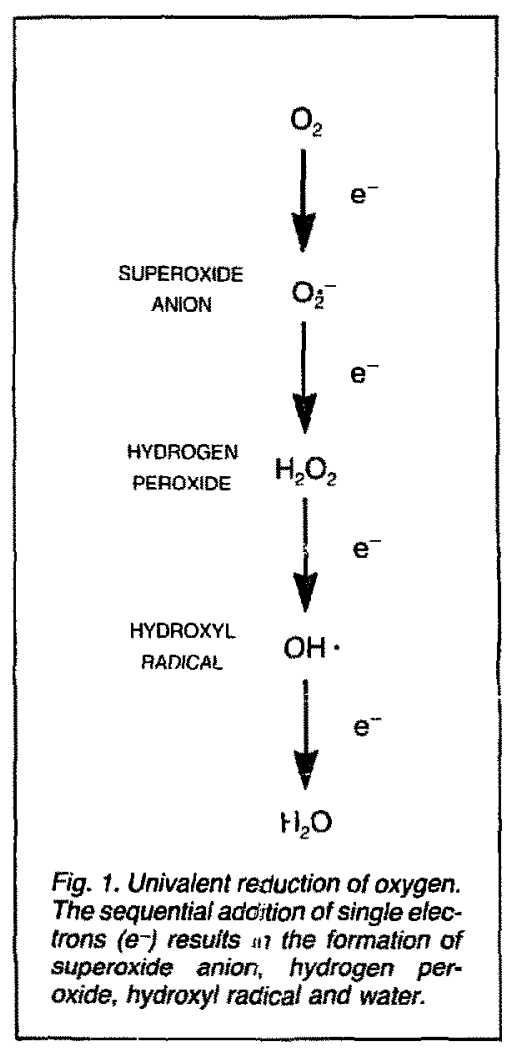




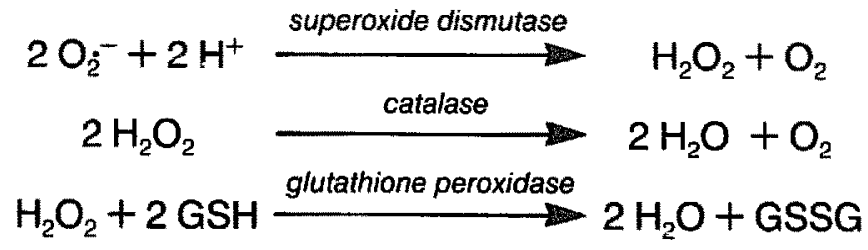

Fig. 2. Reactions catalysed by endogenous antioxidant anzymes. GSH, glutathione; GSSG, glutathione disulfide.

confers an extended plasma halflife). However, the efficacy of SOD has been challenged by other investigators who failed to observe a beneficial effect four or seven days after reperfusion in dogs undergoing coronary artery occlusion for $40 \mathrm{~min}$ or $90 \mathrm{~min}$ (Ref. 14). Tanaka $e t$ al. ${ }^{18}$ reported that PEG-SOD does not limit canine infarct size after $90 \mathrm{~min}$ of ischemia and four days of reperfusion. In this study, the total dose was $10000 \mathrm{U} \mathrm{kg}^{-1}$, which resulted in a plasma concenuration of $330 \mathrm{U} \mathrm{ml}^{-1}$ at the onset of reperfusion. In the study by Tamura et al. ${ }^{17}$, the total dose was $1000 \mathrm{U} \mathrm{kg}^{-1}$, which yielded a plasma concentration of $17 \mathrm{U} \mathrm{ml}^{-1}$ at the onset of reperfusion ${ }^{17}$. Paradoxically, the larger dose may have been responsible for the negative results obtained by Tanaka et al. ${ }^{18}$ Omar et al. ${ }^{19} \mathrm{ob}-$ served that $5 \mathrm{mg} \mathrm{kg}^{-1}$ of human SOD significantly reduced infarct size in the rabbit, while a dose of $15 \mathrm{mg} \mathrm{kg}^{-1}$ did not limit infarct size, and a dose of $50 \mathrm{mg} \mathrm{kg}^{-1}$ significantly increased infarct size. Further work is required to explain the apparent toxicity of large doses of SOD. However, Ooiwa et al. ${ }^{20}$ failed to observe a reduction in infarct size with PEG-SOD $\left(1000 \mathrm{U} \mathrm{kg}^{-1}\right)$ in rabbit heart examined three days after occlusion-reperfusion. The authors raise the question of whether the discrepant results are due to species differences or to the method used to quantitate infarct size.

\section{Effects of neutrophil inhibition or depletion on infarction}

Results from several laboratories support the hypothesis that activated neutrophils are the primary source of oxygen radicals during the reperfusion of myocardium after prolonged regional ischemia. Rabbit or sheep antisera to canine neutrophils can be used to render dogs neutropenic. Dogs treated in this way exhibited less myocardial injury after $90 \mathrm{~min}$ of regional myocardial ischemia followed by reperfusion for up to $72 \mathrm{~h}$ than did dogs treated with saline or a non-immune scrum ${ }^{21}$.

A recently isolated monoclonal antibody, designated Mol 904 binds to the $\alpha$ subunit of both canine and human Mol, which is a heterodimeric adhesion-promoting glycoprotein expressed on the plasma membrane of neutrophils and mononuclear phagocytes ${ }^{22}$. The Mol 904 antibody does not induce neutropenia, and has been demonstrated to inhibit the binding of $\mathrm{C} 3$ bi-opsonized particles and neutrophil aggregation. [Activation of the complement system results in opsonization of injured tissue by $\mathrm{C} 3 \mathrm{bi}$, which directs activated neutrophils to the injury.] Administration of the Mol antibody, or $F\left(a b^{\prime}\right)_{2}$ fragments of the antibody, beginning $45 \mathrm{~min}$ after coronary artery occlusion, significantly reduced infarct size in dogs undergoing $90 \mathrm{~min}$ of occlusion followed by reperfusion for up to $72 \mathrm{~h}$ (Ref. 22). These results provide additional evidence that myocardial injury d:iring reperfusion may be reducrd by suppressing the neutrophilmediated injury that is superimposed on ischemic cell injury.

Inhibition of neutrophil function may explain the cardioprotective actions of a number of diverse agents, including adenosine, perfluorochemicals, ibuprofen, and prostaglandins such as $\mathrm{PGE}_{1}$, prostacyclin and iloprost, a prostacyclin analogue 23,24 .

\section{Myocardial 'stunning' and free radicals}

The delayed recovery of contractile function by viable myo- cardium after ischemia and reperfusion has been referred to as myocardial 'stunning ${ }^{25}$. There is growing evidence that the formation of oxygen radicals during ischemia and/or reperfusion plays a role in the myocardial contractile dysfunction exhibited by myocardium injured 'reversibly' by a brief period of ischemia insufficient to cause necrosis (reviewed in Ref. 24). The most widely used experimental protocol to investigate the pathogenesis of 'stunned' myocardium involves the measurement of regional systolic wall thickening or segment shortening before and after occlusion of a canine coronary artery for $15 \mathrm{~min}$.

\section{Free radical scavengers}

A variety of free radical scavengers have been reported to improve the recovery of myocardial function in dogs subjected to coronary artery occlusion for $15 \mathrm{~min}$ (Table II). Three independent laboratories have reported that the combination of SOD and catalase improved the return of wall thickening or segment shortening after $15 \mathrm{~min}$ of ischemia followed by reperfusion for $2 \mathrm{~h}$ or $3 \mathrm{~h}$ (Ref. 25). Dimethylthiourea (DMTU), a putative scavenger of hydroxyl radicals, and the low molecular weight sulfhydryl compound MPG enhance the recovery of 'stunned' myocardium ${ }^{13,25}$. Myocardial stunning was also attenuated by treatment with deferoxamine, which may prevent formation of hydroxyl radicals by chelating iron ${ }^{25}$. The beneficial effects of DMTU and deferoxamine have been interpreted as evidence for dysfunction caused by hydroxyl radicals. Deferoxamine, however, also may function as a scavenger of peroxyl radicals ${ }^{26}$. Recent data indicate that DMTU and deferoxamine may be capable of preventing injury by hypochlorous acid, a

TABLE II. Agents that attenuate myocardia stumning

- Deleroxamine

- Superoxide dismutase plus catalase

- Sulfhydryl compounds N-2-mercaptopropionyl glycins cirnethylthiourea $N$-acetylcysteine captopril

- Xanthine oxidase inhibitors allopurinol oxipurinol 
product of activated neutrophils 27.28 , but there are conflicting data regarding the role of neutrophils in the pathogenesis of myocardial stunning (see below).

Until recently, the relative importance of ischemia and reperfusion in the development of postischemic myocardial dysfunction was unknown because the free radical scavengers had been administered before the onset of myocardial ischemia in all the studies of myocardial stunning. Bolli et al. ${ }^{13}$ have now demonstrated that the administration of MPG either before coronary artery occiusion or immediately before the onset of reperfusion significantly improves the recovery of contractile function after $15 \mathrm{~min}$ of ischemia, whereas treatment be ginning $1 \mathrm{~min}$ after reperfusion does not enhance the recovery of myocardial function. Production of free radicals is me edly suppressed by infusion of MPG immediately before reperfusion, while a burst of free radical production occurs during the first minute of reperfusion in the dogs receiving MPG $1 \mathrm{~min}$ after reperfusion. This suggests that most of the free radical injury responsible for myocardial stunning begins during the first minute of reperfusion.

\section{Neutrophil inhibition or depletion}

There is disagreement regarding the role of neutrophils in the pathogenesis of myocardial stun- ning. Treatment with iloprost, a prostacyclin analogue that inhibits the production of superoxide anions by activated neutrophils, increased systolic segment shortening after $15 \mathrm{~min}$ of ischemia and $3 \mathrm{~h}$ of reperfusion, while the myocardial function of dogs treated with an equihypotensive dose of sodium nitroprusside was similar to that of controls ${ }^{29}$, and coronary perfusion with blood rendered agranulocytic by extracorporeal filters prevented myocardial stunning ${ }^{25}$. However, stunning was not prevented by a $90 \%$ reduction of the circulating neutrophil count in dogs treated with an antibody that had previously been shown to limit infarct size after 90 min of ischemia $^{25}$. Furthermore, treat-
Activated species of oxygen generated by the enzyme xanthine oxidase have been postulated to cause cellular injury during reperfusion of ischemic tissuel. The role of xanthine oxidase in the pathogenesis of ischemic myocardial iniury, however, is controversial. There is evidence that myocardial xanthine dehydrogenase, which does not generate oxygen radicals, is converted to xanthine oxidase during regional myocardial ischemia ${ }^{1,2}$, but the effects of xanthine oxidase inhibitors on experimental myocardial infarction have been variable.

Treatnent with allopurinol beginning at least one day before coronary artery occlusion limited the extent of canine myocardial injury after coronary artery occlusion for $60 \mathrm{~min}$ (Ref. 2) or 90 min (Ref. 3) followed by reperfusion for $4 \mathrm{~h}$ or $6 \mathrm{~h}$, respectively. Dogs treated with allopurinol for $48 \mathrm{~h}$ before coronary artery occlusion exhibited less myocardial stunning than controls after regional ischemia for $15 \mathrm{~min}$ followed by reperfusion*

The beneficial effects of allopurinol appear to require a period of chronic pretreatment before coronary artery occlusion, since administration beginning either $30 \mathrm{~min}$ before coronary artery occlusion ${ }^{5}$ or $15 \mathrm{~min}$ before reperfusion ${ }^{6} \mathrm{did}$ not reduce the extent of myocardial injury. The inefficacy of the acute treatment regimens suggested that the alleviation of xanthine oxidase-mediated myocardial injury by allopurinol, a competitive enzyme inhibitor, might require a longer treatment schedule that permits the metabolic conversion of allopurinol to its active metabolite, oxipurinol - a noncompetitive inhibitor with a longer half-life? $\mathrm{f}^{7}$. Therefore, it has been postulated that the accumulation of xanthine and hypoxanthine, the substrates of xanthine oxidase, within ischemic myocardium, might attenuate the inhibition of xanthine oxidase by allopurinol, while not affecting inhibition by oxipurinol ${ }^{7}$.

Several studies have examined the effect of oxipurinol on canine infarct size. The administration of oxipurinol $15 \mathrm{~min}$ berore and $3 \mathrm{~h}$ after reperfusion significantly reduced the extent of myocardial injury in dogs undergoing coronary artery occlusion for 90 min followed by reperfusion for $6 \mathrm{~h}$ (Ref. 6). Administration of a dose of oxipurinol before coronary occlusion or before reperfusion did not limit the

\section{Does myocardial injury result from $\mathrm{f}$}

ultimate extent of myocardial infarction in dogs subjected $40 \mathrm{~min}$ or $90 \mathrm{~min}$ of ischemia followed by one day or fo days of reperfusion ${ }^{8-10}$. This is consistent with previous $d$ that indicated that short-term administration of a drug $\mathrm{m}$ merely delay tissue injury, while sustained therapy may required to prevent infarction. The infusion of iloprost prostacyclin analogue, throughout the period of corona occlusion and the initial $2 \mathrm{~h}$ of reperfusion limited the ext of myocardial injury assessed after $6 \mathrm{~h}$ but not $72 \mathrm{~h}$ reperfusion ${ }^{11}$. Iloprost therapy that was continued until 4 after reperfusion, however, significantly reduced the ext of injury assessed $72 \mathrm{~h}$ after reperfusion ${ }^{11}$.

One possible explanation of the conflicting results scribed above is that low doses of allopurinol may incres reperfusion injury by reducing the concentration of $u$ acid, which may act as a scavenger of free radicals. Zhong al. ${ }^{12}$ recently reported the effects of allopurinol on exp? imental liver damage caused by low-flow ischemia follow by reperfusion. Low doses of allopurinol actually increas cell injury, while higher doses of allopurinol prevented death completely ${ }^{12}$. The authors proposed that high conce trations of uric acid are required to prevent injury caused free radicals, so that partial inhibition of xanthine oxida by low doses of allopurinol could decrease the uric a concentrations below that required to scavenge the sup oxide anions generated by the residual xanthine oxide activity.

Recent observations have provided reason to reconsig: the hypothesis that xanthine oxidase plays a role in pathogenesis of post-ischemic myocardial injury. First, th is evidence that the myocardial protection afforded treatment with either allopurinol or oxipurinol may not related to inhibition of xanthine oxidase. Allopurinol reported to limit ischemic myocardial injury in both rabbit and the pig, although xanthine oxidase activity $w$ not detected in the myocardium of either species ${ }^{13,14}$. Al treatment with amflutizole, which is a more potent inhibi of xanthine oxidase than either allopurinol or oxipurin did not reduce either myocardial stunning or infarct size the dog, supporting the conclusion that allopurinol a oxipurinol may limit post-ischemic myocardial injury b 
ment with the Mol antibody (which reduces infarct size after $90 \mathrm{~min}$ of ischemia) did not prevent myocardial stunning after $15 \mathrm{~min}$ of ischemia ${ }^{30}$. There was no significant accumulation of neutrophils during reperfusion of the myocardium after occlusion of a canine coronary artery for 12 min (Ref. 31), supporting the conclusion that neutrophils do not contribute to myocardial dysfunction after reversible injury. Thus, although one study has suggested that leukocytes cause the contractile dysfunction of reversibly injured myocardium, it appears that this dysfunction cannot be prevented by a clinically feasible approach such as the administration of a monoclonal antibody.

\section{Xanthine oxidase inhibit?rs}

Treatment with allopurinol improved systolic wall thickening after 15 min of regional ischemia, and oxypurinol enhanced regional contractile function after $90 \mathrm{~min}$ of coronary artery occlusion ${ }^{25}$. However, the effects of allopurinol and oxipurinol may be unrelated to xanthine oxidase inhibition, and there is controversy regarding the presence of xanthine oxidase activity in human heart (see Box).

\section{Global myocardial ischemia and free radicals}

Experimental preparations of global cardiac ischemia have been used as models of myocardial injury associated with cardioplegia during cardiopulmonary bypass or preservation for cardiac transplantation. Several experimental end-points have been used: left ventricular compliance and systolic function; tissue ultrastructure; the release of cytoplasmic constituents such as creatine kinase or lactate dehydrogenase; and the loss of metabolic substrates such as adenosine triphosphate and creatine phosphate. Each of the experimental end-points has been affected favorably by the administration of a free radicai scavenger during global cardiac ischemia. In addition, EPR data have been interpreted as evidence for free radical production by isolated hearts after global is shemia ${ }^{10,11}$, and deferoxamine enharced the functional

\section{icals produced by xanthine oxidase?}

chanism unrelated to the inhibition of xanthine oxidase ivity ${ }^{15,16}$. Indeed, it has been suggested that the beneficial ects of allopurinol involve enhanced purine salvage ${ }^{17}$.

On the basis of in-vitro data, it has been proposed that purinol serves as a scavenger of hydroxyl radicals ${ }^{18}$ or pochlorous acid ${ }^{19}$, an oxidant produced by activated 1trophils. Hypochlorous acid and its derivatives may mote tissue injury by the inactivation of $\alpha_{1}$-antitrypsin, ich protects tissue elastin from hydrolysis by elastase ${ }^{20}$. ipurinol, but not allopurinol, has been observed to vent the inactivation of $\alpha_{1}$-antitrypsin by hypochlorous ${ }^{19}$. Treatment with allopurinol that was adequate to rmit formation of oxipurinol, however, did not increase ability of feline plasma or lymph to scavenge hypoorous acid or inhibit lipid peroxidation induced by drogen peroxide plus myoglobin 21 . Thus, there are conting data regarding the capacity of allopurinol therapy to bvide protection against oxidants.

The other reason for questioning the importance of thine oxidase is that biochemical assays have not ected xanthine oxidase activity in homogenates of human ocardium 22-24 (although immunohistochemical techues have been reported to demonstrate the enzyme's sence in the capillary endothelium of the human heart ${ }^{25}$ ). cently, it was reported that the human heart produced $c$ acid during transient myocardial ischemia induced by onary angioplasty, indicating the presence of xanthine hydrogenase/oxidase activity ${ }^{26}$. Measurement of xanthine dase activity by chemiluminescence indicated the sence of substantial xanthine oxidase activity in human jilical vein endothelial cells ${ }^{27}$, which also have been wn to release superoxide anions after hypoxia followed reoxygenation ${ }^{28}$. Thus, additional studies are needed to ermine the mechanism of action of allopurinol and purinol, and further scrutiny of the xanthine oxidase ivity of human cardiac vascular endothelium may be rranted.

\section{erences}

McCord, J. M. (1985) N. Engl. J. Med. 312, 159-163
2 Chambers, D. E. et al. (1985) J. Mol. Cell. Cardiol. 17, 145-152

3 Werns, S. W., Shea M. J. and Mitsos, S. E. (1986) Circulation 73, 518-524

4 Charlat, M. L. et al. (1087) Am. J. Physiol. 252, H566-H577

5 Reimer, K. A. and Jennings, R. B. (1985) Circulation 71, 1069-1075

6 Werns, S. W., Grum, C. M., Ventura, A. and Lucchesi, B. R. (1987) Circulation 76, IV-97

7 Spector, T. (1988) Biochem. Pharmacol. 37, 349-352

8 Kinsman, J. M., Murry, C. E., Richard, V. J., Jennings, R. B. and Reimer, K. A. (:988) J. Am. Coll. Cardiol. 12, $209-217$

9 Puett, D. W. et al. (1987) Circulation 76, 678-686

10 Richard, V. J., Murry, C. E., Jennings, R. B. and Reimer, K. A. (1988) Circulation 78, 473-480

11 Simpson, P. J., Fantone, J. C., Mickelson, J. K., Gallagher, K. P. and Lucchesi, B. R. (1988) Circ. Res. 63, 1070-1079

12 Zhong, Z., Lemasters, J. J. and Thurman, R. G. (1989) I. Pharmacol. Exp. Ther. 250, 470-475

13 Godin, D. V. and Bhimji, S. (1987) Biochem. Pharmacol. 36, 2101-2107

14 Das, D. K. et al. (1987) Biochem. Biophys, Res. Commun. 148, 314-319

15 Werns, S. Ventura, A., Li, G. C. and Lucchesi, B. R. (1989) Circulation 80, II-295

16 Werns, S. W., Ventura, A., Hahn, R. A. and Lucchesi. B. R. (19:39) FASEB I. 3, A1021

17 Lasley, R. D., Ely, S. W., Berne, R. M. and Mentzer, R. M. (1988) J. Clin. Invest. 81, 16-20

18 Eey, B. M., Butler, I. and Halliwell, B. (1988) Free Radical Res. Commun. 4, 259-263

19 Grootveld, M., Halliwell, B. and Moorhouse, C. P. (1988) Froe Radical Res. Commun. 4, 69-76

20 Weiss, S. J. (1989) N. Engl. J. Med. 320, 365-375

21 Zimmerman, B. J., Parks, D. A., Grisham, M. B. and Cranger, D. N. (1988) Am. J. Physiol. 255, H202-H206

22 Eddv, L. J. et al. (1987) Am. J. Physiol. 253, H709-H711

23 Grum, C. M., Gallagher, K. P., Kirsh, M. M. and Shlafer, M. (1989) Mol. Cell. Cardiol. 21, 263-267

24 Muxfeldt, M. and Schaper, W. (1987) Basic Res. Cardiol. 82, $486-492$

25 Jarasch, E-D., Bruder, G. and Heid, H. W. (1986) Acta Physiwl. Scand. 548, 39-46

26 Huizer, T. et al. (1939) I. Mol. Cell. Cardiol. 21, 691-695

27 Bailey, I. A., Blackweli, C. P. and Woodward, B. (1988) Basic Res. Cardiol. 83, 392-400

28 Schinetti, M. L., Sbarbati, R and Scarlattini, M. (1989) Cardiovasc. Res. 23, 76-80 
recuvery of isolated hearts after global ischemia ${ }^{32}$. Numerous other studies have described the beneficial effects of free radical scavengers on the function of rat, rabbit, doy and porcine hearts perfused with various crystalloid solutions before and after global myocardial ischernia.

Many investigators have proposed that the enzyme xanthine oxidase is the primary source of free radicals under such conditions. However, xanthine oxidase activity is either absent or is confined to the endothelium of rabbit, porcine and human hearts, and the effect of allopurinol on cardiac tissue may not be related to inhibition of xanthine oxidase (see Box). Thus, the free radicals produced by crystalloid-perfused hearts probably emanate from mitochondria, the sarcoplasmic reticulum, or other sources. It may be incorrect to presume that the hearts perfused with asanguinous solutions retain insufficient phagocytic cells to account for significant production of free radicals. A recent study concluded that the resident mast cells of the crystalloid-perfused rat heart are an important cause of injury during post-hypoxic reoxygenation ${ }^{33}$.

The role of free radicals in the pathogenesis of myocardial stunning after reversible myocardial injury has been supported by numerous experimental studies. There have been inconsistent results, however, with respect to the ability of free radical scavengers to limit irreversible myocardial injury caused by prolonged myocardial ischemia. The conflicting data may relate to the differing experimental protocols and dosing regimens.

Despite the disagreement among experimental studies, preliminary results of two clinical trials were reported recently ${ }^{34,35}$. A randomized, double-blind, placebocontrolled, multicenter trial compared treatment with human recombinant SOD vs placebo in 114 patients who underwent coronary angioplasty for acute myocardial infarction ${ }^{34}$. Treatment with SOD did not alter the recovery of left ventricular ejection fraction or regional wall motion assessed by both contrast ventriculography one week after infarction and radionuclide ventriculography six weeks after infarction. This study has several deficiencies: inadequate sample size (if the true effect of SOD on the change in ejection fraction is an increase of $5 \% 170$ patients would be required in order to achieve $90 \%$ statistical significance); the brief duration of therapy ( $1 \mathrm{~h})$; and relatively late reperiusion ( $4 \mathrm{~h}$ after the onset of chest pain).

Forman et al.35 reported an improvement in left ventricular function in patients with acute anterior myocardial infarction who underwent coronary angioplasty followed by intracoronary infusion of perfluamine (FluosolDA), a perfluorochemical that has been demonstrated to limit canine infarct size and inhibit free radical production by neutrophils. The results of only 11 patients were reported, however. Thus, further experimental and clinical studies will be required in order to prove that free radicals play an important role in the pathogenesis of myocardial infarction.

\section{References}

1 Halliwell, B. and Gutteridge, I. M. C. (1986) Arch. Biochem. Biopilys. 246, 501-514

2 Grisham, M. B. and McCord, M. J. (1986) in Physiology of Oxygen Radicals (Taylor, A. E., Matalan, S. and Ward, P., eds), pp. 1-18, American Physiological Society

3 Ytrehus, K, Myklebust, R. and Mjos, R. (1986) Cardiovasc. Res, 20, 597-603

4 Hess, M. L., Okabe, E., Ash, P. and Kontos, H. A. (1984) Cardiovasc. Res. 18 , 149-157

5 Guarnieri, C., Flamigni, F. and Caldarera, C. M. (1980) I. Mol. Cell. Cardiol. 12, 797-808

6 Winterbourn, C. C. and Stern, A. (1987) l. Clin. Invest. 80, 1486-1491

7 Brown, J. M. et al. (1989) Am. J. Physiol. 256, H584-H588

8 Romaschin, A. D., Rebeyka, : Wilson G. J. and Mickle, D. A. G. (1987) ]. Mol. Cell. Cardiol. 19, 289-302

9 Brasch, H., Schoenberg, M. H. and Younes, M. (1989) I. Mol. Cell. Cardiol. 21, 697-707

10 Zweier, J. L. (1988) J. Biol. Chem. 263 1353-1357

11 Garlick, P. B., Davies, M. J., Hearse, D. J and Slater, T. F. (1987) Circ. Res. 61 $757-760$

12 Bolli, R. et al. (1989) Proc. Natl Acad. Sci. USA 86, 4695-4699

13 Bolli, R. et al. (1989) Circ. Res. 65, 607-622

14 Engler, R. and Gilpin, E. (1989) Circuiation 79, 1137-1142

15 Mitsos, S. E. et al. (1986) I. Cardiovasc. Pharmacol. 8, 978-988

16 ;olly, S. R., Kane, W. J., Bailie, M. B.,
Abrams, G. D. and Lucchesi, B. R. (1984) Circ. Res. 54, 277-285

17 Tamura, Y. et al. (1988) Circulation 63 944-959

18 Tanaka, M., FitzHarris, G. I'., Stoler, R. C., Jennings, R. B. and Reimer, K. A. (1989) Circulation 80, II-296

19 Omar, B. A., Jordan, M. C., Downey, J. M. and McCord, J. M. (1989) Circulation 80, II-294

20 Ooiwa, H., Jordan, M., BylundFellehius, A-C. and Downey, J. M. (1989) Circulation 80, II-294

21 Simpson, P. I., Fantone, J. C., Mickelson, J. K., Gallagher, K. P. and Lucchesi, B. R. (1988) Circ. Res. 63, 1070-1079

22 Todd, R. F., Simpson, P. J. and Lucchesi, B. R. (1989) in Structure and Function of Molecules lnvolved in Leukocyte Adhesion (Springer, T. A., Anderson, D. C., Rosenthal, A. S. and Rothlein, R., eds), pp. 125-137, Springer-Verlag

23 Werns, S. W. and Lucchesi, B. R. (1988) Free Radical Biol. Med. 4, 31-37

24 Forman, M. B., Puett, D. W. and Virmani, R. (1989) J. Am. Coll. Cardiol. $13,450-459$

25 Bolli, R. (1988) I. Am. Coll. Cardiol. 12, 239-249

26́ Darley-Usmar, V. M., Hersey, A. and Garland, L. G. (1989) Biochem. Pharmacol. $38,1465-1469$

27 Klebanoff, S. J. and Waltersdorph, S. J. (1988) Arch. Bivitiem. Biophys. 264, 600-606

28 Wasil, M. et al. (1987) Biochem. I. 243, $867-870$

29 Farber, N. E., Pieper, G. M., Thomas, J. P. and Gross, G. J. (1988) Circ. Res. 62, 204-215

30 Schott, R. J. et al, (1989) Circ. Res. 65, 1112-1124

31 Gu, L. O. et al. (1988) Am. I. Physiol. 255, H1188-H1198

32 Ambrosio, G., Zweier. J. L., Jacobus. W. E. Weisfeldt, M. L. and Flaherty J. T. (1987) Circulation 76, 906-915

33 Keller, A. M., Clancy, R. M., Barr, M. L. Marboe, C. C. and Cannon, P. J. (1988) Circ. Res. 63, 1044-1052

34 Werns, S. ei al. (1989) Circulation 80 II-113

35 Forman, M. B. et al. (1989) Circulation 80 , II-112

\section{Awards}

\section{Gilman wins Gilman}

Al Gilman has been chosen as recipient of this year's prestigious ASPET prize established in honour of his father. The Louis S. Goodman and Alfred Gilman Award in Drug Receptor Pharmacology was awarded at this year's FASEB meeting in Washington in acknowledgement of Gilman's formative work on $G$ proteins. 